\title{
Cerrahi kliniğinde yatan 65 yaş üstü hastaların düşme risklerinin belirlenmesi
}

\section{Determination of falling risks of patients over 65 years old in the surgical clinics}

\author{
Esma Özşaker1 (D) , Feray Yapsu² ${ }^{\mathbb{D}}$, Güler Demir Yılmaz \\ ${ }^{1}$ Ege Üniversitesi Hemşirelik Fakültesi Cerrahi Hastalıkları Hemşireliği Anabilim Dalı, İzmir \\ 2 Şişli Hamidiye Etfal Eğitim ve Araştırma Hastanesi, İstanbul \\ 3 Torbalı Devlet Hastanesi, İzmir
}

Öz.

Amaç: Bu çalışma bir üniversite hastanesinin cerrahi kliniklerinde yatan 65 yaş üstü hastaların düşme riskinin belirlenmesi amacıyla yapıldı.

Materyal ve Metod: Tanımlayıcı tipte olan bu araşıımanın örneklemini bir üniversite hastanesinin cerrahi kliniklerinde yatan 65 yaş üstü, çalışmaya katılmayı kabul eden 120 hasta oluşturdu. Veriler, hastaların bireysel özelliklerini içeren anket formu ve ITAKI Düşme Riski Ölçeğin' den yararlanılarak toplandı. Veriler sayı, yüzde, ortalama gibi tanımlayıcı istatistiksel yöntemler ve ki-kare analizi ile değerlendirildi.

Bulgular: Araştırmada, hastaların $\% 71,6$ 'sının $65-74$ yaş aralığında, $\% 53,3$ 'ünün kadın, $\% 50,8$ 'inin lise mezunu olduğu belirlendi. Hastaların \%15'inin son 1 yıl içinde düşme öyküsünün olduğu ve $\% 4,1^{\prime \prime i n i n ~ k l i n i k t e ~ y a t t ı g ̆ ı ~ s u ̈ r e ~ i c ̧ i n d e ~ d u ̈ s ̦ t u ̈ g ̆ u ̈ ~}$ belirlendi. Hastaların ITAKi Düşme Riski Ölçeği puan ortalamasının 13,94 $\pm 8,18$ olduğu ve $\% 79,2$ 'sinin yüksek düşme riskine sahip olduğu saptandı. Hastaların cinsiyeti, ameliyat öncesi ya da sonrası dönemde olma durumu ile düșme riski arasında anlamlı bir ilişki bulunmadı $(p>0,05)$. Düşme riskine karşı alınan önlemler incelendiğinde ise hastaların $\% 62,5^{\prime}$ inin yanında sürekli refakatçi bulunduğu, \%86,7'sinin yatak kenarlığının kaldıııldı̆ı̆, \%5'inde hekim istemi doğrultusunda sedatif ilaç uygulandığı, \%2,5'inde fiziksel tespit kullanıldığı, \%50,8'ine hareket ve diğer aktivitelerini gerçekleştirmede yardım edildiği saptanmışıtı.

Sonuç: Bu sonuçlar cerrahi kliniklerinde yatan 65 yaş üstü hastaların bireysel ve çevresel faktörlerden dolayı düşme risklerinin yüksek olduğunu göstermektedir. Ülkemizdeki yaşıı nüfusun yıllar geçtikçe artış göstermesi, hastanelerde; hasta güvenliğinin önemli bir parçası olan düşmelerin önlenmesi için stratejilerin gözden geçirilmesini, yaşlı hastalarda düşme riskinin değerlendirilmesini ve gerekli önlemlerin alınmasına önem verilmesini gerektirmektedir.

Anahtar kelimeler: Düşme riski, Hasta güvenliği, Yaşlı, Cerrahi,

\section{Abstract}

Backgrounds: This study was carried out to determine the risk of falls of patients over 65 years old in the surgical clinics of a university hospital.

Methods: The sample of this descriptive study consisted of 120 patients who agreed to participate in the study over 65 years of age in the surgical clinics of a university hospital. The data were collected by using a questionnaire including individual characteristics of patients and by using the ITAKi Falling Risk Scale. Data were analyzed by descriptive statistical methods such as number, percentage, mean, and chi-square analysis.

Results: In the study, $71.6 \%$ of the patients were in the $65-74$ age range, $53.3 \%$ were female and $50.8 \%$ were high school graduates. It was determined that $15 \%$ of the patients had a history of fall in the last 1 year and $4.1 \%$ of the patients fell within the period they were in the clinic.

The mean Itaki Fall Risk Scale scores of the patients was $13.94 \pm 8.18$ and $79.2 \%$ of the patients were in the high risk group. There was no significant relationship between the gender of the patients and the preoperative or postoperative period and the risk of falling ( $p>0.05)$

Taking into consideration of the precautions against fall risks, it has been designated that bed guards of $86.7 \%$ of the patients were removed, $62.5 \%$ of the attendants were left unattended, $86.7 \%$ of the bed border is increased, in $5 \%$ of patients, sedative drug is applied according to the request of physician, $2.5 \%$ of the physical determination is used, $50.8 \%$ to assist in carrying out activities and other activities.

Conclusions: These results indicate that patients over 65 years of age in the surgical clinics are at higher risk of falling due to individual and environmental factors. The increase in the elderly population in our country over the years, in hospitals; review strategies to prevent falls, which is an important part of patient safety, assessment of the risk of falling in elderly patients and taking the necessary precautions.

Keywords: Falling Risk, Patient safety, Olderly, Surgery

\section{Sorumlu Yazar I Corresponding Author}

Dr. Esma ÖZŞAKER

Ege Üniversitesi Hemşirelik Fakültesi Cerrahi Hastalıkları Hemşireliği Anabilim Dalı, İzmir

\section{Tel: +90 2323115500}

e-mail: esmaozseker@yahoo.com

Geliş tarihi / Received: 22/11/2018

Kabul tarihi / Accepted: 23/07/2019

Bu çalışma, 2. Uluslararası 11. Ulusal İzmir Ileri Yaş Sempozyumu 21-22 Mart 2018, Izmir'de poster bildiri olarak sunulmuştur.

\section{DOI: 10.35440/hutfd.486797}




\section{Giriş}

Türkiye İstatistik Kurumu 2016 yılı verilerine göre; son beş yılda yaşlı nüfusun \%17,1 arttığı ve ülkemizde yaşlı nüfusun 2016 yılında 6 milyon 651 bin 503 kişi olduğu belirtilmektedir (1). Yaşllık ve yaşın ilerlemesi ile artan fiziksel yetersizliğin düşme riskini artıran bir faktör olduğu belirtilmektedir (2). Her yıl toplumda yaşayan 65 yaş üzeri yetişkinlerin \%30-40'ı düşmekte, 80 yaş ve üzeri kişilerde bu oran \%50'ye kadar yükselmektedir (3).

Hasta güvenliği kaliteli sağlık hizmetinin en önemli göstergelerinden biridir (4-6). Düşmeler, bütün dünyada sağlık bakım kurumlarında önemli bir hasta güvenliği problemi olarak belirtilmekte $(4,6-8)$ hastanelerde en sık görülen kazalar arasında yer almakta $(2,9)$ ve aynı zamanda bakım kalitesini yansıtmaktadır (8). Özellikle 65 yaş ve üstü kişilerin hastanelerde karşılaştığı yaralanma ve ölümlerin en önemli nedeninin düşmeler olduğu $(2,10)$, düşmelerin önlenmesinden primer olarak hemşirelerin sorumlu olduğu belirtilmektedir (4).

Yabancı ortam, yaşlılık, kullanılan bazı ilaçlar, bilişsel bozukluklar, görme ve işitme kayıpları, kas kuvvetinin ve reflekslerin azalması düşme riskini artıran bireysel risk faktörleri arasında yer almaktadır $(2,4,7,11)$. Düşme, özellikle yaşlı kişilerde yaralanma ve fonksiyon kayıplarına neden olarak hastanede kalış süresinin uzamasına, tedavi maliyetinin artmasına, günlük yaşam aktivitelerini etkileyerek bireyin yaşam kalitesinin azalmasına, aynı zamanda hasta ve hastane personelinde anksiyete ve korku gelişmesine neden olduğundan önemlidir $(3,6,10,12,13)$. Düşmelerin neden olduğu bu sonuçlar, düşsme riskinin belirlenmesi ve önlenmesinin önemini ortaya koymaktadır (12). Düşme riski değerlendirmesinin, hastanın kuruma kabulünde, klinikler arası taşınması esnasında, hastanın genel durumunda bir değişiklik olması durumunda yapılması önerilmektedir (14). Literatürde yaşlılarda düşmeye yol açan risk etmenlerini tanılamaya yönelik çeşitli tanılama ya da risk değerlendirme araçları bulunmaktadır. Bu alanda ülkemizde ve yurtdışında kullanılan Morse Düşme Riskleri Belirleme Ölçeği, STRATIFY, Hendrich II, Schimed, ITAKI Düşme Riski Belirleme Ölçeği, Huzurevlerinde Düşmeyle Ilişkili Risk Faktörlerini Değerlendirme ölçeği gibi pek çok düşme risk tanılama aracı vardır (15). Bunun dışında ülkemizde hasta güvenliği uygulamalarının bir parçası olan düşmelerin önlenmesi konusunda farklı ölçekler gözden geçirilerek ITAKI Düşme Riski Belirleme Ölçeği geliştirilmiştir. İlgili ölçek hasta düşmelerine neden olabilecek risk faktörlerini içermekte olup ülkemizde Performans Yönetimi ve Kalite Geliştirme Daire Başkanlığı tarafından kullanıması önerilmektedir (16).

Düşme risklerinin bireysel değerlendirilmesiyle düşmeyi önlemek için ne tür önlemler alınacağına karar verilmektedir (14). Hemşireler, düşme riskini değerlendirerek bireyin düşme riskini önceden belirlemeli ve düşmeyi azaltmaya yönelik hemşirelik müdahalelerinde bulunmalıdır (8). Hastaların hastane ortamında düşmesinin tamamen önlenemeyeceği ancak uygulanacak etkin koruyucu önlemler ile en aza indirilebileceği belirtilmektedir (2).

Bu çalışma bir üniversite hastanesinin cerrahi kliniklerinde yatan 65 yaş üstü hastaların düşme riskinin belirlenmesi amacıyla yapıldı.

\section{Materyal ve Metot}

Tanımlayıcı tipte olan bu araştırmanın verileri Şubat- Aralık 2014 tarihleri arasında toplandı. Çalışmanın örneklemini bir üniversite hastanesinin cerrahi kliniklerinde yatarak tedavi gören 65 yaş üstü, cerrahi girişim geçiren ya da geçirecek ve çalışmaya katılmayı kabul eden 120 hasta oluşturdu.

Veriler, hastaların bireysel özelliklerini içeren anket formu ve ITAKI Düşme Riski Ölçeğin' den yararlanılarak toplandı. Hasta Tanıtım Formu: Bireyin geçmiş deneyimleri, yaşı, cinsiyeti, eğitim düzeyi, mesleği, sağlık güvencesi, daha önceden hastanede yatma deneyimi, ikamet ettiği yer, ekonomik durumu vb. düşme riskini etkileyebilmektedir. Bu durumlar göz önüne alınarak hastalara ait tanıtıcı bilgileri elde etmek amacıyla 14 sorudan oluşan "Hasta Tanııı Formu" kullanıldı.

ITAKI Düşme Riski Ölçeği: Cerrahi hastalarının düşme risklerinin belirlenmesi amacıyla "ITAKI Düşme Riski Ölçeği" kullanıldı. Ölçek hasta düşmelerine neden olabilecek risk faktörlerini içerecek şekilde, toplam 19 risk faktöründen oluşmaktadır. Risk faktörleri majör ve minör olarak kategorize edilerek minör risk faktörlerine 1 puan, majör risk faktörlerine ise 5 puan verilmektedir. Risk faktörlerinin değerlendirilmesi sonucu elde edilen toplam puan üzerinden düşük ve yüksek olmak üzere iki risk düzeyi belirlenmektedir. Hastanın düşme riski düzeyi, toplam puanı 5 'in altında ise düşük risk, 5 ve 5 'in üzerinde ise yüksek risk olarak değerlendirilmektedir $(16,17)$.

Veriler, araştırmanın yapılacağı kurumdan çalışma izni alındıktan sonra toplanmaya başlandı. Araştırmaya katılmayı kabul eden 65 yaş üstü hastalara araştırmanın amacı açıklandı ve sözlü onay alındıktan sonra veriler yüz yüze görüşme tekniği kullanılarak toplandı. Her bir hasta ile görüşme süresi yaklaşık 10 dakika sürdü. Çalışmada elde edilen veriler bilgisayar ortamına aktarılarak sayı, yüzde, ortalama ile değerlendirildi.

\section{Bulgular}

Araştırmada, hastaların yaş ortalamasının $71,34 \pm 6,04$ yaş olduğu (En az:65, En çok:90), \%71,6'sının 65-74 yaş aralığında, \%53,3'ünün kadın, \%50,8'inin lise mezunu, $\% 58,3$ 'ünün (n:70) evli ve \%88,3'ünün (n:106) sosyal güvencesi olduğu belirlendi (Tablo 1). Araştırma kapsamına alınan hastaların \%90'ının (n:108) daha önce hastaneye yattığı, \%55,8'inin (n:67) yanında sürekli refakatçisinin kaldığı, hastaların \%60'ının ( $\mathrm{n}: 72$ ) ameliyat sonrası dönemde 
olduğu belirlendi (Tablo 2).

Araştırmaya katılan hastaların son 1yıl içinde düşme durumları incelendiğinde yalnızca \%15'inin (n:18) düşme öyküsünün olduğu, klinikte yattığı süre içinde düşme durumları incelendiğinde \%4,1'inin (n:5) klinikte düştüğü, alınan önlemler incelendiğinde daha çok yatak kenarlığının yükseltme $(\% 86,7)$ ve yanında sürekli refakatçi bırakılma $(\% 62,5)$ önlemlerinin alındığı belirlendi (Tablo 3). Araştırmaya katılan hastaların ITAKI Düşme Riski Ölçeği puan ortalamasının 13,94 $\pm 8,18$ olduğu, düşme riski incelendiğinde \%79,2'sinin (n:95) yüksek risk grubunda olduğu belirlendi (Tablo 4). Hastaların yaş grubu, cinsiyeti ve ameliyat öncesi ya da sonrası dönemde olma durumu ile düşme riski arasında anlamlı bir ilişki bulunmadı $(p>0,05)$. Cerrahi kliniklerde yatan yaşlı hastalarda ITAKI düşme risk faktörlerinin görülme yüzdeleri Tablo 5'te görülmektedir (Tablo 5).

Tablo 1. Hastaların Sosyo-Demografik Özelliklerine Göre Dağı-

\begin{tabular}{llll} 
Iımı & & $\mathrm{n}$ & $\%$ \\
\hline Hasta tanıtıcı bilgiler & & 86 & 71,6 \\
\hline Yaş & $65-74$ & 86 & 23,3 \\
& $75-84$ & 6 & 5,0 \\
Cinsiyet & 85 ve üzeri & & \\
& Erkek & 56 & 46,7 \\
Eğitim durumu & Kadın & 64 & 53,3 \\
& İlköğretim & 14 & 11,7 \\
& Ortaöğretim & 29 & 24,2 \\
& Lise & 61 & 50,8 \\
Meslek & Yükseköğretim & 16 & 13,3 \\
& Isşi & 5 & 4,2 \\
& Memur & 2 & 1,7 \\
& Ev hanımı & 29 & 24.2 \\
& Esnaf & 0 & 0 \\
& Serbest meslek & 1 & 0,8 \\
Medeni Durum & Emekli & 83 & 69,2 \\
& Evli & 70 & 58,3 \\
Sosyal güvencesi & Olan & 106 & 88,3 \\
olma durumu & Olmayan & 14 & 11,7 \\
\hline
\end{tabular}

\section{Tartışma}

Hastanede yatan hastaların düşme riski düzeyinin belirlenmesi, düşme risk yönetiminin sağlanması, hastaların düşme insidansının ve şiddetinin azaltılması, hastanın kendini güvende hissetmesi açısından önemlidir. Hastane ortamında düşmeler, hasta güvenliğini olumsuz yönde etkileyen olaylardır.

Hastanede düşen hastalarda yaşın önemli bir faktör olduğunu 60-65 yaş grubunun yüksek risk, 80 yaş ve üzerinin çok daha yüksek risk oluşturduğu vurgulanmaktadır (18). Düşme sıklığının yaşla birlikte arttığı ve yaşamsal faktörlere bağlı olarak değiştiği belirtilmektedir. 65 yaş üstünde, sağlıklı ve toplum içinde yaşayanlarda kişi başı yıllık düşme oranı \%30-40 iken, uzun dönem bakım merkezlerinde yaşayanlarda \% $50^{\prime}$ lere çıkmaktadır. Literatürde, yaşIIlık ve yaşın ilerlemesi ile artan fiziksel yetersizliğin düşme riskini artıran bir faktör olduğu belirtilmektedir (17). Araştırma kapsamına alınan hastaların \%71,6'sının 65-74 yaş aralığında olduğu, yaş ortalamalarının $71,34 \pm 6,04$ olduğu, yaş grubu ile düşme riski arasında istatistiksel olarak anlamlı bir ilişki olmadığı bulundu. Bu çalışmada, yaş grubu ile düşme riski arasında anlamlı bir ilişki olmama nedeninin, tüm bireylerin 65 yaş üstünde olmasına bağlı olduğu düşünülmektedir.

Tablo 2. Hastaların Hastaneye Yatma ve Ameliyat Olma Durumlarına Göre Dağılımı

\begin{tabular}{|c|c|c|c|}
\hline & & $\mathrm{n}$ & $\%$ \\
\hline \multirow{2}{*}{$\begin{array}{l}\text { Daha önce hastanede } \\
\text { yatma durumu }\end{array}$} & Yatan & 108 & 90 \\
\hline & Yatmayan & 12 & 10 \\
\hline \multirow{3}{*}{$\begin{array}{l}\text { Refakatçinin kalış du- } \\
\text { rumu }\end{array}$} & Refakatçi yok & 32 & 26,7 \\
\hline & Sürekli kalıyor & 67 & 55,8 \\
\hline & Belli saatlerde kalıyor & 21 & 17,5 \\
\hline \multirow{4}{*}{$\begin{array}{l}\text { Hastanede yatış sü- } \\
\text { resi }\end{array}$} & 1 haftadan az & 25 & 20,8 \\
\hline & 1-2 hafta & 64 & 53,3 \\
\hline & 2-4 hafta & 25 & 20,8 \\
\hline & 1 aydan fazla & 6 & 5,0 \\
\hline \multirow[t]{2}{*}{ Hastaneye yatış şekli } & Acil servisten & 52 & 43,3 \\
\hline & Planlı cerrahi & 68 & 56,7 \\
\hline \multirow{2}{*}{$\begin{array}{l}\text { Ameliyat } \\
\text { rumu }\end{array}$} & Ameliyat öncesi dönem & 48 & 40,0 \\
\hline & Ameliyat sonrası dönem & 72 & 60,0 \\
\hline
\end{tabular}

Tablo 3. Hastaların Düşme Durumu ve Alınan Önlemler

\begin{tabular}{|c|c|c|c|}
\hline & & $\mathrm{n}$ & $\%$ \\
\hline \multirow{2}{*}{$\begin{array}{l}\text { Son bir yıl içinde } \\
\text { düşme öyküsü }\end{array}$} & Bulunan & 18 & 15,0 \\
\hline & Bulunmayan & 102 & 85,0 \\
\hline Klinikte yattığı & Bulunan & 5 & 4,1 \\
\hline $\begin{array}{l}\text { süre içerisinde } \\
\text { düşme öyküsü }\end{array}$ & Bulunmayan & 107 & 89,2 \\
\hline \multirow[t]{5}{*}{$\begin{array}{l}\text { Düşmelerini Ön- } \\
\text { lemek Amacıyla } \\
\text { Alınan Önlemler }\end{array}$} & $\begin{array}{l}\text { Klinikte hastanın yanında } \\
\text { sürekli refakatçi bırakıl- } \\
\text { ması }\end{array}$ & 75 & 62,5 \\
\hline & $\begin{array}{l}\text { Yatak kenarlığının yüksel- } \\
\text { tilmesi }\end{array}$ & 104 & 86,7 \\
\hline & $\begin{array}{l}\text { Hekim istemi doğrultu- } \\
\text { sunda sedatif ilaç uygu- } \\
\text { lama }\end{array}$ & 6 & 5 \\
\hline & Fiziksel tespit kullanımı & 3 & 2,5 \\
\hline & $\begin{array}{l}\text { Hareket ve diğer aktivitele- } \\
\text { rini gerçekleștirmede yar- } \\
\text { dım edilmesi }\end{array}$ & 61 & 50,8 \\
\hline
\end{tabular}


Tablo 4. Hastaların ITAKi Düşme Riski Ölçeği Puan Ortalamaları ve Düşme Riski

\begin{tabular}{lll}
\hline & $\mathbf{n}$ & $\mathbf{X} \mathbf{S S}$ \\
\hline $\begin{array}{l}\text { ITAKi Düşme Riski Ölçeği Puan Ortala- } \\
\text { ması }\end{array}$ & 120 & $13,94 \pm 8,18$ \\
\hline Düşme Riski Düzeyi & $\mathbf{n}$ & $\%$ \\
\hline Düşük risk & 25 & 20,8 \\
Yüksek risk & 95 & 79,2 \\
\hline
\end{tabular}

Tablo 5. Cerrahi Kliniklerde Yatan Yaşlı Hastalarda ITAKI Düşme Risk Faktörlerinin Görülme Yüzdeleri

\begin{tabular}{llll}
\hline & MiNOR RiSK FAKTÖRLERI & $\mathbf{n}$ & $\%$ \\
\hline 1 & 65 yaş ve üstü & 120 & 100 \\
2 & Bilinci kapalı & 8 & 6,7 \\
3 & Son 1 ay içinde düşme öyküsü bulunan & 18 & 15 \\
4 & Kronik hastalık öyküsü bulunan & 113 & 94,2 \\
5 & Ayakta fiziksel desteğe (yürüteç, koltuk/kişi desteği & 51 & 42,5 \\
& vb.) intiyacı olan & 49 & 40,8 \\
6 & Üriner/fekal kontinans bozukluğu olan & 92 & 76,7 \\
7 & Görme durumu zayıf & 62 & 51,7 \\
8 & 4'den fazla ilaç kullanımı & 47 & 39,2 \\
9 & Hastaya bağı 3'ün altında bakım ekipmanı bulunan & 10 & 8,3 \\
10 & Yatak korkulukları bulunmayan/çalışmayan & 2 & 1,7 \\
11 & Yürüme alanlarında fiziksel engel(ler) olan & $\mathrm{n}$ & $\%$ \\
\hline & MAJÖR RisK FAKTÖRLERi & - & - \\
\hline 12 & Bilinç açık, koopere değil & 44 & 36,7 \\
13 & Ayakta/yürürken denge problemi olan & 63 & 52,5 \\
14 & Baş dönmesi olan var. & 84 & 70 \\
15 & Ortostatik hipotansiyonu & - & - \\
16 & Görme engeli olan & 9 & 7,5 \\
17 & Bedensel engeli olan & 4 & 3,3 \\
18 & Hastaya bağlı 3 ve üstü bakım ekipman bulunan & 26 & 21,7 \\
19 & Son 1 hafta içinde riskli ilaç kullanımı olan & &
\end{tabular}

Bu çalışmada, hastaların \%4,1'inde son 1 yıl içinde düşme olayı gerçekleştiği belirlendi. Savcı ve arkadaşlarının (2009) nöroloji ve nöroşirurji kliniklerinde hastaların düşme riski ve alınan önlemlerin belirlenmesi amacıyla yaptıkları çalışmada düşme oranı \%0,9; Sanar ve ark.'nın (2013) bir devlet hastanesinin dahiliye ve cerrahi servislerinde düşme riski, alınan önlemlerin belirlenmesi ve yönetimi amacıyla yaptıkları çalışmada düşme oranı $\% 0,3$ olarak bulunmuştur $(17,18)$. Bu çalışmada oranın daha yüksek olma nedeni araştırma kapsamına alınan hastaların 65 yaş üstü olmalarından kaynaklandığı düşünülmektedir.

Cerrahi servisinde yatan ve araştırmaya katılan 65 yaş ve üstü hastaların düşme riski ölçeği puan ortalaması 13,94 $\pm 8,18$ olarak bulundu. Sanar ve ark.'nın (2013), Bir Devlet Hastanesinin Dahiliye ve Cerrahi Servislerinde Düşme Riski, Alınan Önlemlerin Belirlenmesi ve Yönetimi amacıyla yaptıkları çalışmada 65 yaş ve üstü 119 hastada düşme riski puan ortalaması $11,65 \pm 6,35$ bulunmuş olup çalışmamızla benzerlik göstermektedir (17). Yaşlılık düşmelerini önlemede öncelikle, risk altındaki bireylerin belirlenmesi ve sonra yaralanmaları önlemek/azaltmak için etkili girişimlerin planlanması, uygulanması ve sonuçların değerlendirilmesi önerilmektedir (14). Hastanede görülen düşmelerin \%80'ninden fazlasının 65 yaş üzeri hastalarda görüldüğü bildirilmektedir (19). Bu çalışmada da ITAKI düşme riski ölçeğine göre araştırmaya katılan bireylerin büyük çoğunluğunun $(\% 79,2)$ yüksek risk grubunda olduğu saptandı. Savcı ve arkadaşlarının (2009) nöroloji ve nöroşirurji kliniklerinde hastaların düşme riski ve alınan önlemlerin belirlenmesi amacıyla yaptıkları çalışmada Hendrich II Düşme Riski Modeline göre 61 ve üzeri yaş grubunda yer alan hastaların \%56,52'sinin düşme riskinin yüksek olduğu, Çeçen ve Özbayır'ın (2011) cerrahi kliniklerde yatan yaşlı hastaların düşme risklerinin belirlenmesi ve düşmeye yönelik alınan önlemlerin değerlendirmesi amacıyla yaptıkları çalışmada hastaların Hendrich Düşme Riski Ölçeğine göre \%38'inin yüksek düşme riski, \%62'sinin ise düşük düşme risk grubunda oldukları saptanmıştı (18). Demir ve ark. (2016) tarafından yapılan çalışmada da hastaların yaş ortalamasının 67,9 yaş olduğu ve $\% 66,6$ 'sında düşme riskinin yüksek olduğu saptanmıştır (12). Yaşın ilerlemesiyle ortaya çıkan bazı fizyolojik değişiklikler ve kronik hastalıkların düşme riskini artmaktadır (8). Karaman Özlü ve ark.(2015) tarafından yapılan çalışmada da 66 yaş ve üzerinde olan cerrahi hastalarının $\% 67,7$ 'sinin yüksek risk grubunda oldukları saptanmıştır (9). Literatür $(8,9)$ ile uyumlu olarak bu çalışmada 65 yaş üstü hastalarla çalışıması diğer çalışmalara göre düşme riskinin daha yüksek olma sonucunu açıklamaktadır. Bu bulgu, cerrahi servislerde yaşı hastalara bakım verilmesi sırasında düşmeyi önlemek üzere koruyucu önlemlerin uygulanmasına yönelik yeni stratejilerin gerektiğini göstermektedir.

Kadınların menopoza bağlı olarak kemik mineral yoğunluğunda erkeklere göre daha fazla kayıp yaşamaları nedeniyle erkeklerden daha yüksek düşme olasılığına sahip oldukları belirtilmektedir (10). Bu çalışmada hastaların cinsiyeti ile düşme riski arasında anlamlı bir ilişki bulunmadı $(p>0,05)$. Bizim çalışma sonucunu destekler nitelikte Karaman Özlü ve ark.'nın (2015) cerrahi hastalarılla yaptıkları çalışmada ve Çeçen ve Özbayır'ın (2011) cerrahi kliniklerde yatan yaşlı hastalarla düşme risklerini belirlemeye yönelik yaptıkları çalışmada cinsiyetin düşme riski ile ilişkisinin olmadığı saptanmıştır $(9,14)$.

Bu çalışmada hastaların ameliyat öncesi ya da sonrası dönemde olma durumu ile düşme riski arasında anlamlı bir ilişki bulunmadı ( $p>0,05)$. Bu çalışmadan farklı olarak Karaman Özlü ve ark. (2015)'in cerrahi hastalarında yaptıkları çalışmada ameliyat sonrası dönemde düşme riskinin anlamlı derecede yüksek olduğu belirlendi $(p<0,05)(9)$. Bizim çalışmamızda ameliyat öncesi ya da sonrası dönemde bulunma durumu ile düşme riski arasında anlamlı fark bulunmama nedeninin düşme riskinin çok yüksek olduğu 65 yaş 
ve üstü hastalar ile çalışılmış olmasından kaynaklandığı düşünülmektedir.

\section{Sonuç ve Öneriler}

Bu sonuçlar cerrahi kliniklerinde yatan 65 yaş üstü hastaların düşme risklerinin yüksek olduğunu göstermektedir. Ülkemizdeki yaşı nüfusun yıllar geçtikçe artış göstermesi göz önünde bulundurularak, hastanelerde hasta güvenliğinin önemli bir parçası olan düşmelerin önlenmesi amacıyla; stratejilerin gözden geçirilmesi, yaşlı hastalarda düşme riski ölçekleri ile yüksek riskli hastaların tespit edilmesi ve gerekli tedbirler alınması, hasta ve ailesinin düşme olasılığına karşı alacağı kişisel önlemler hakkında bilgilendirilmesi, düşme riski yüksek olan servislerde çalışan hemşire sayısının arttırılması ve yüksek riske sahip hastalara hareket ve diğer aktivitelerini gerçekleştirmede yardım edilmesi önerilmektedir

\section{Kaynakça}

1. TÜIK. Türkiye İstatistik Kurumu Haber Bülteni, 16 Mart 2017 tarih ve 24644 sayılı yazı.

2. Bozdemir H., Küçükberber N., Özmen S. Kocaeli Üniversitesi Araştırma ve Uygulama Hastanesinde Yatan Hastalarda Düşme Sonuçlarının Değerlendirilmesi. Online Türk Sağılı Bilimleri Dergisi 2016; 1(2): 6-16.

3. Eyigör S. Düşmelere Yaklaşım, Ege Journal of Medicine 2012; 51: 43-51.

4. Duman S., Kitiş Y. Yoğun Bakımda Çalışan Hemşirelerin Hasta Düşmeleri İle İlgili Farkındalıklarının Belirlenmesi. Türk Yoğun Bakım Derneği Dergisi 2013; 11: 72-9.

5. Joint Commission International. Joint Commission International Accreditation Standards For Hospitals 4. Edition 2011; p. 35, 145. Erişim (http://www. hastane.ege.edu.tr/duyurular/TKY/files/ JCIA_Standards_Hospitals_4th_Edition. pdf) Erişim tarihi: 21 Nisan 2013

6. Oyur Çelik G., Zıngal H. Beyin Cerrahisi Kliniğinde Yatan Hastaların Düşme Risklerinin ve Alınan Önlemlerin Belirlenmesi. İzmir Kâtip Çelebi Üniversitesi Sağlık Bilimleri Fakültesi Dergisi 2016; 1(1): 711.

7. Morse JM. Preventing Patient Falls 2. Edition, Springer Publishing Company 2009; 7-71. http://www.springerpub.com/samples/9780826103895_chapter.pdf Erişim tarihi: 11 Şubat 2012.

8. Özden D., Karagözoğlu Ş., Kurukız S. Hastaların İki Ölçeğe Göre Düşme Riskinin Belirlenmesi Ve Bu Ölçeklerin Düşmeyi Belirlemedeki Duyarlıı̆̆: Pilot Çalışma. Anadolu Hemşirelik ve Sağlık Bilimleri Dergisi 2012; 15(1): 80-88.

9. Karaman Özlü Z., Yayla A., Özer N., Gümüș K., Erdağı S., Kaya Z. Cerrahi Hastalarda Düşme Riski. Kafkas J Med Sci 2015; 5(3): 9499.

10. Gale CR., Cooper C., Sayer AA. Prevalence and risk factors for falls in older men and women: The English Longitudinal Study of Ageing. Age and Ageing 2016; 45: 789-794.

11. Berke D., Eti Aslan F. Cerrahi Hastaların Bekleyen Bir Risk: Düşmeler, Nedenleri ve Önlemler. Anadolu Hemşirelik ve Sağlık Bilimleri Dergisi 2010; 13(4): 72-77.

12. Demir MV., Taycı I.., Yıldız H., Öztürk Demir T. Dahiliye Yoğun Bakım Hastalarının Düşme Riski Açısından Değerlendirilmesi. J hum rhythm 2016; 2(3): 122-125.

13. Tunçay Uz., Özdinçler R., Erdinçler D. Geriatrik Hastalarda Düşme Risk Faktörlerinin Günlük Yaşama Etkileri ve Yaşam Kalitesine Etkisi, Turkish Journal of Geriatrics 2011; 14: 245-252.

14. Çeçen D., Özbayır, T. Cerrahi Kliniklerinde Yatan Yaşıı Hastalarda
Düşme Riskinin Belirlenmesi Ve Düşmeyi Önlemeye Yönelik YapıIan Girişimlerin Değerlendirilmesi, Ege Üniversitesi Hemşirelik Yüksek Okulu Dergisi 2011; 27 (1): 11-23.

15. Ekşiuymaz P., Nahçivan N. Yaşlılar İçin Düşme Davranışları Ölçeği'nin Geçerlik ve Güvenirliği, F.N. Hem. Derg 2013; 21(1): 2232.

16. Performans Yönetimi ve Kalite Geliştirme Daire Başkanlığı (2011). ITAKI Düşme Riski Belirleme Ölçeği, http://www.kalite.saglik.gov.tr (02.12.2012).

17. Sanar S., Demirci H., Taşçıoğlu S. Bir Devlet Hastanesinin Dahili ve Cerrahi Servislerinde Düşme Riski, Alınan Önlemlerin Belirlenmesi ve Yönetimi. In: Beylik U., Önder Ö. Eds:. 3. Ulusal Sağlıkta Kalite ve Güvenlik Ödülleri Kitabı, Ankara: Bakanlık Yayın, 2013:316.

18. Savcı C., Kaya H., Acaroğlu R., Kaya N., Bilir A., Kahraman H., Gökerler N. Nöroloji ve Nöroşirurji Kliniklerinde Hastaların Düşme Riski ve Alınan Önlemlerin Belirlenmesi. Maltepe Üniversitesi Hemşirelik Bilim ve Sanatı Dergisi 2009; 2(3): 19-25.

19. Healey FA. Guide on How to Prevent Falls and Injury in Hospital. Nursing Older People 2010; 22(9): 16-22. 